\title{
The effects of self-reference versus other reference on the recall of traits and nouns
}

\author{
RUTH H. MAKI and KEVIN D. McCAUL \\ North Dakota State University, Fargo, North Dakota
}

\begin{abstract}
Although self-reference often facilitates recall, this effect is not always obtained, and the present experiments were designed to discover when self-reference produces better memory than other reference does. In Experiment 1, subjects decided either whether trait adjectives described themselves, their mothers, and Ronald Reagan, or whether each of these persons used different objects (nouns). On an incidental recall task, traits that had been paired with the self were remembered better, but the opposite effect was obtained for nouns. In Experiment 2, an imagery explanation of the differential effects of nouns and traits was investigated. Regardless of imagery instructions, self-reference enhanced recall for traits but not for nouns. Self-reference seems to facilitate memory only when the to-be-remembered materials are part of the self- or some other known-person schema. Traits-but not nouns-fit this description.
\end{abstract}

The recent integration of cognitive and social psychology has prompted research interest in what has come to be termed the self-schema (Markus, 1977; Markus \& Smith, 1981). Much of this research has centered on selfreference effects on memory, consistent with the proposal that the self can be characterized as a set of well-articulated memory structures (Greenwald, 1981). Such a depiction implies that material encoded with reference to the self should be processed to a deep level, leading to high recall (Craik \& Tulving, 1975). In an early demonstration supporting this contention, Rogers, Kuiper, and Kirker (1977) showed that asking whether particular traits were selfdescriptive resulted in better subsequent recall for those traits than did asking whether the traits had various semantic properties. Bower and Gilligan (1979) similarly demonstrated that pairing personal episodes (e.g., a boring lecture) with the self led to better later recall of the episodes than did processing them for semantic meaning.

Self-reference enhances memory not only more than semantic processing does, but also more than processing with reference to other individuals. Keenan and Baillet (1980) found a linear effect of familiarity and memory: the more familiar the person, the better the memory for traits linked to that person. Words linked to the self (the most "familiar" person) consistently were recalled best. Kuiper and Rogers (1979) reported a similar effect: traits processed in terms of the self were remembered better than traits processed in terms of an unfamiliar other.

There are conditions, however, in which self-reference fails to increase recall. Generally, self-reference is no

We would like to thank Kathleen M. Brady, Eva Miller, Mary Ann Roalkvam, and Michael W. Vasey for helping to conduct the experiments and Janice M. Keenan for her helpful comments on an earlier version of this manuscript. Requests for reprints or for an extended version of this paper should be sent to Ruth Maki at the Department of Psychology, North Dakota State University, Fargo, ND 58105. better than reference to a familiar other (Bower \& Gilligan, 1979; Kuiper \& Rogers, 1979). Moreover, Keenan and Baillet (1980) and Lord (1980) found that selfreference is no better than reference to an unfamiliar other under some conditions. Lord (1980) asked subjects to imagine either themselves, their fathers, or Walter Cronkite interacting with a variety of objects (e.g., a boat). Imagining oneself interacting with the objects produced lower recall for those objects than for objects imagined with father or Cronkite. Keenan and Baillet (1980) asked subjects questions about persons who varied in familiarity (including the self) or about cities that varied in familiarity. Half of the questions were factual in nature (e.g., "does your parent have gills?"), and half of the questions were evaluative (e.g., "does exciting describe the city you've never been to?'). On a subsequent recognition task for the words, familiarity facilitated memory-but only for evaluative judgments. Higher familiarity (i.e., the self or a city in which you live) failed to increase recognition when factual judgments were made. Therefore, as did Lord (1980), Keenan and Baillet (1980) found that self-reference does not inevitably enhance memory.

\section{EXPERIMENT 1}

The purpose of the present research was to determine when self-reference enhances memory more than other reference does. Keenan and Baillet (1980) and Lord (1980) described two conditions in which self-reference fails to enhance memory more than other reference does: when the self is used in images and when factual, as opposed to evaluative, questions are asked. In Experiment 1, we tested another explanation that could account for the above findings. Specifically, in each of the conditions in which the self failed to enhance memory, the words to be remembered were nouns. In contrast, studies using 
traits have shown that words processed in terms of the self were better remembered than words processed with respect to others.

In Experiment 1, we predicted that the recall of traits but not nouns would be better when words were processed in terms of the self than when they were processed in terms of an unfamiliar other (Ronald Reagan). This prediction was based both on the research discussed above and on speculation about the content of the self-schema. Theoretically, memory facilitation for material processed with reference to the self should occur only when the material can be organized around the self-schema. This organization may be more likely when traits are processed than when nouns are processed because traits may be an integral part of the self-schema (Markus, 1977), whereas the self-schema may not contain general objects (Markus \& Smith, 1981).

\section{Method}

Subjects and Materials. Twenty-nine subjects participated individually to obtain extra credit for introductory psychology. Sixteen subjects were assigned randomly to the traits condition, and 13 to the noun condition.

Two 48-word lists, one of trait adjectives and one of nouns, were presented to subjects on an Apple II computer. The traits were drawn from the ratings of Anderson (1968); half had been rated positive and half negative. The nouns were drawn from Paivio, Yuille, and Madigan (1968). All nouns referred to objects and made sense with the question "Do you use?" In the trait condition, each word was presented following one of three question stems: "Do you think you are?", "Do you think your mother is?", or "Do you think Ronald Reagan is?" In the noun condition, the question stems were "Do you think you use?", "Do you think your mother uses?", and "Do you think Ronald Reagan uses?" Each set of words (nouns and traits) was formed into six subgroups of eight words each. For each subject, two of these subgroups were paired randomly with each of the three stimulus persons.

Procedure. The subjects learned that they would be making judgments about different people. The subjects in the trait condition were told that they would be asked to decide whether different personality characteristics described them, their mothers, and Ronald Reagan. The subjects in the noun condition were told that they would be asked to decide whether the same persons used different objects. In both conditions, the subjects responded "yes" or "no" by pressing one of two keys. After a subject had answered, the screen went blank for a 3-sec interval prior to presentation of the subsequent question and word. After all 48 words had been presented, the subjects were given 4 min to free-recall as many of the words as they could.

\section{Results}

For each subject, the numbers of "yes" and "no" responses to the stimulus words were summed. The proportion of those words that were recalled was then computed,since words given "yes" responses are better remembered than words given "no" responses (Craik \& Tulving, 1975). These data, portrayed in Figure 1, reveal a different recall pattern, depending on the person referenced and whether the question concerned traits or nouns. As predicted, trait recall was highest for traits that were paired with the self, but noun recall was highest for nouns that were paired with Reagan.

A 2 (word type) $\times 3$ (person) $\times 2$ (response) unweighted-means, mixed-design ANOVA was performed on the recall data, resulting in three reliable effects. A main effect of word type demonstrated that a greater proportion of nouns than of traits was recalled

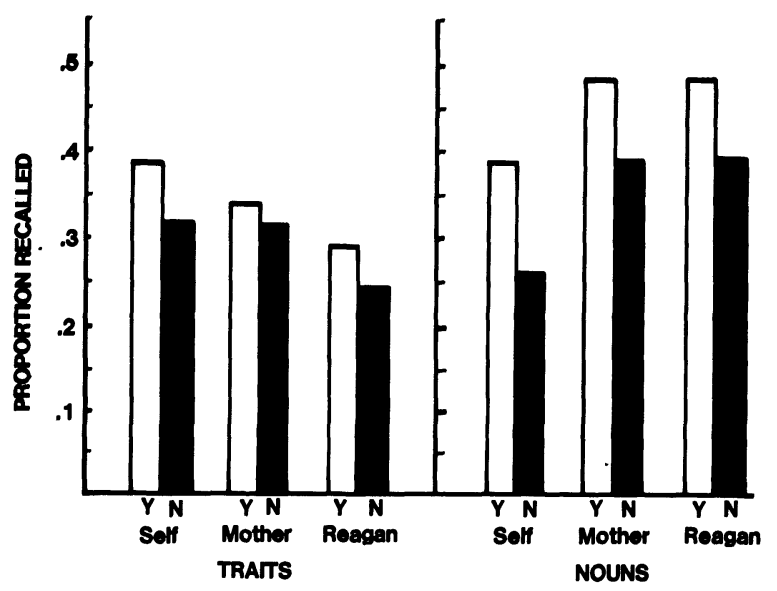

Figure 1. Average proportion of traits and nouns recalled as a function of "yes"- "no" responses and stimulus person-Experiment 1.

$[\mathrm{F}(1,27)=4.95, \mathrm{p}<.05$ (the significance level used to report all significant results, unless otherwise noted)]. A main effect of response demonstrated that "yes"; responses produced higher recall than did "no" responses $[(1,27)=5.28]$. Finally, the expected word type $\times$ person interaction was obtained $[\mathrm{F}(2,54)=3.63]$.

To examine the interaction, two nonorthogonal but theoretically interesting interaction contrasts were performed. Self versus mother was examined in a 2 (word type) $\times$ 2 (person) $\times 2$ (response) ANOVA. This analysis revealed no significant effects involving person, which indicates that reference to one's mother was as effective (or ineffective) for recall as self-reference was. Recall for self versus Reagan was tested in a similar analysis, and produced a reliable word type $\times$ person interaction $[(1,27)$ $=7.30 \mathrm{]}$. As the means in Figure 1 show, self-reference tended to facilitate recall when subjects answered questions about traits $(p=.06)$ and to hinder recall when subjects answered questions about nouns $(p=.09)$.

\section{Discussion}

Generally, the data fit with our predictions. The interaction between person and word type was significant. For traits, recall tended to be better for self-reference, but these results were reversed for nouns: Pairing nouns with Reagan tended to produce better recall than pairing the nouns with oneself. Pairing words with one's mother produced results for both traits and nouns that were intermediate to the effects for self and Reagan. However, the difference between self and mother was not significant in either word-type condition, which replicated a result reported by Bower and Gilligan (1979). It is reasonable to assume that the self-schema is more integrated than knowledge about Reagan, and this may have produced the difference in recall of traits paired with the self and Reagan. However, the difference in knowledge about ourselves and our mothers may not be great enough to produce differences in this type of recall task.

The overall pattern of results suggests that our alternative explanation for the findings of Keenan and Baillet (1980) and those of Lord (1980) is reasonable. Self-reference facilitated recall only for traitsnot for nouns. This was true even with a relatively evaluative question with nouns. In addition, we suspect that Lord's explanation of his data is inappropriate for our results. Lord theorized that self-reference fails to improve memory under imagery instructions, because self-images do not actually include a representation of oneself. Subjects do not "see" themselves, making the image a poor link for later recall. Because we 
did not give imagery instructions, it is doubtful that the subjects formed images in the noun condition. However, because the names of concrete objects were used, the words were easily imageable and images could have been formed even in the absence of instructions. We manipulated the likelihood of image formation in Experiment 2.

\section{EXPERIMENT 2}

Experiment 2 varied both materials (nouns vs. trait adjectives) and instructions between subjects. One-half of the subjects were instructed to form images of themselves, a friend, or Ronald Reagan, either using objects (nouns) or behaving in certain ways (traits). The other half of the subjects were given reaction time (RT) instructions. They were asked to indicate how often they, their friend, or Ronald Reagan used various objects or how often these individuals showed various traits. The RT instructions (i.e., "respond as fast as possible") were designed to minimize the use of imagery, since the formation of images takes more time than the understanding of words (Paivio, 1971, p. 76). Since self- and mother reference produced similar effects in Experiment 1, we used an other less well known than mother in this experiment. The subjects were asked to provide the name of someone who was a friend.but not a close friend. We thought that decreasing the familiarity of a known other might produce results that were intermediate to those for self and Reagan.

\section{Method}

Subjects and Materials. Forty-eight subjects from introductory psychology were assigned randomly to the four word-type and task conditions. There were 12 subjects in each condition.

The word lists from Experiment 1 were used. For each subject, 16 words were assigned randomly to the self condition, 16 to the friend condition, and 16 to the Reagan condition. The order in which words were presented was randomized for each subject.

Procedure. On each trial, the question stems and traits or nouns were presented by computer. In the noun-imagery condition, each noun was preceded by "Imagine (person) using a(n).," In the trait-imagery condition, each trait was preceded by "Imagine (person) being." "Yourself," "Reagan," or the friend's name was inserted in place of "(person)" on each trial. In both of these conditions, a 4-point scale matching the four positions on a joystick was displayed at the bottom of the screen. The up, down, left, and right positions contained the words "very vivid," "fairly vivid," "fairly fuzzy," and "very fuzzy," respectively. The subjects were instructed to move the joystick in the direction that best designated the clarity of each image. In the noun-RT condition, each noun was preceded by "(Person) use(s)," and in the trait-RT condition, each trait was preceded by "(Person) are (is)." At the bottom of the screen, the up, down, left, and right positions contained the phrases "very often," "fairly often," "rarely," and "almost never." In the RT conditions, the subjects were instructed to move the joystick as fast as possible (with accuracy) in the direction indicating the frequency with which each object was used or each trait exhibited. In all conditions, there was a 2-sec intertrial interval between each response and the next trial. After the presentation of the 48 words, the subjects were asked to free-recall as many of the words as possible.

\section{Results}

In Experiment 1, words were classified in terms of whether they received a "yes" or a "no" response, and the proportion recalled in each response condition was analyzed. Although this would also be an appropriate way to analyze the present data, many subjects did not use all four rating values in all conditions; thus, data points were

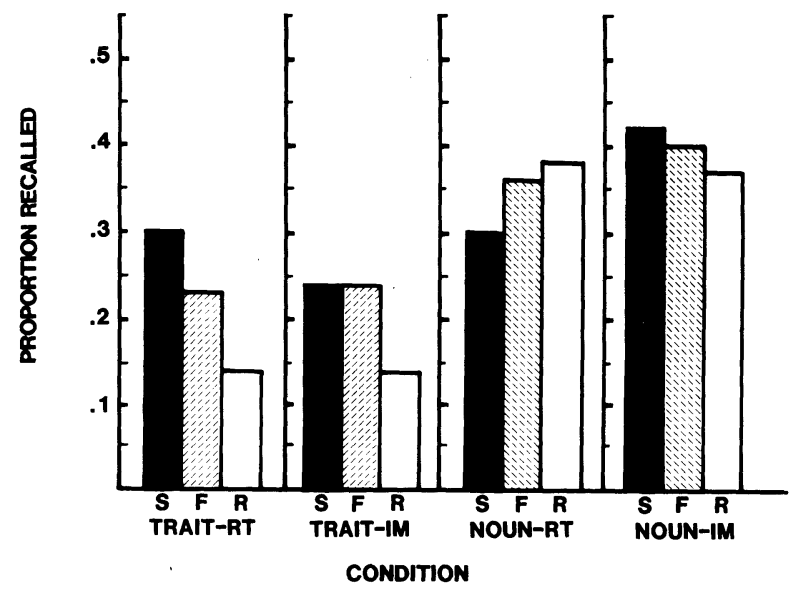

Figure 2. Average proportion of traits and nouns recalled with imagery (IM) and reaction time (RT) instuctions for self (S), friend (F), and Reagan (R)-Experiment 2.

missing. Therefore, the analyses presented below were conducted on the raw number recalled. Proportions recalled for each rating were also analyzed with subjects who had missing data dropped from the analyses. Because those analyses yielded the same conclusions as the raw data analysis, they will not be discussed further.

A task $\times$ word type $\times$ person ANOVA on the number of words recalled was conducted. To be consistent with Figure 1, the recall data in Figure 2 are shown in terms of proportion correct of the 16 words in each person condition. The ANOVA showed two reliable effects. Nouns were remembered better than traits $[F(1,44)=42.16]$, and person and word type interacted $[\mathrm{F}(2,88)=5.74]$. In the trait condition, person produced a reliable main effect $[F(2,44)=9.19]$, such that self-reference led to better recall than did reference to Reagan $[\mathrm{F}(1,11)=19.87$, $\mathrm{p}<.01]$. Reference to a friend and self-reference did not differ $(F<1)$. In the noun condition, there was no effect of person $(F<1)$.

\section{Discussion}

The results suggest that the type of materials, rather than task instructions, is responsible for the different effects of self-reference seen in Experiment 1. The imagery instructions in Experiment 2 failed to alter the pattern of recall in a manner that would be predicted by Lord (1980). His research suggested that imagery instructions would make other reference better than self-reference, but this was not the case in either wordtype condition. Indeed, self-reference tended to be slightly better in the noun-imagery condition, although that difference did not approach statistical significance. In the trait conditions, self-reference was better than reference to an unfamiliar other regardless of imagery instructions.

These experiments were designed to investigate some circumstances in which self-reference produces better memory than other reference does. The data across both experiments are clear: self-reference facilitates memory for traits but fails to improve memory for nouns. These findings are important because they can account for the varied findings of previous research. Lord (1980) found that imagining the self interacting with various objects (i.e., nouns) hindered later recall relative to imagining others interacting with the objects. He suggested an explanation for this finding: We do not "see" ourselves in our images. Experiment 2 did not support this explanation. Instead, our research suggests that Lord's findings were probably due to the use of nouns as stimuli. Keenan and Baillet (1980) also obtained data that can be reinterpreted on the basis of our findings. They suggested that processing 
words in reference to familiar persons aids memory when evaluative, but not factual, judgments are made. As noted previously, though, the manipulation of evaluative versus factual words used by Keenan and Baillet was in terms of traits versus nouns.

Aside from providing a parsimonious explanation of previous research, our findings need to be taken into account when considering the theoretical underpinnings of self-reference effects. Any theoretical account must deal with two sets of results: Self-reference improves memory for traits; it does not improve memory for nouns. We and others (e.g., Kuiper \& Rogers, 1979; Rogers et al., 1977) have proposed that self-reference improves memory only when the to-be-remembered materials can be encoded with respect to a well-organized schema. Nouns may exemplify material that cannot be encoded with respect to the self-schema, and, therefore, they are not facilitated by self-reference. Traits, in contrast, are important components of the self-schema.

It should be noted that the assumption that general objects are not part of an integrated self-schema does conflict with some theories of the self. James (1890) long ago suggested that there exists a "material" self. Indeed, it may that some objects are linked to the self (e.g., one's special running shoes; a wedding ring), but we propose that most common objects are represented only as members of general categories (e.g., newspapers, chairs) and not as part of the self-schema. On the other hand, there may be other "nouns"' that are more relevant to one's selfschema and that would thus show a self-reference effect. One's occupation, for example, may be a strong part of a person's self-description. Tests of whether the latter materials show a self-reference effect would be a fruitful extension of the present research.

\section{REFERENCES}

ANDERSON, N. H. (1968). Likableness ratings of 555 personality-trait words. Journal of Personality and Social Psychology, 9, 272-279.

Bower, G. H., \& GilligaN, S. G. (1979). Remembering information related to one's self. Journal of Research in Personality, 13, 420-432.

Craik, F. I. M., \& Tulving, E. (1975). Depth'of processing and the retention of words in episodic memory. Journal of Experimental Psychology: General, 104, 268-294.

Greenwald, A. G. (1981). Self and memory. In G. H. Bower (Ed.), The psychology of learning and motivation (Vol. 15). New York: Academic Press.

JAMES, W. (1890). The principles of psychology (Vol. 1). New York: Holt.

Keenan, J. M., \& BaIllet, S. D. (1980). Memory for personally and socially stgnificant events. In R. S. Nickerson (Ed.), Attention and Performance VIII. Hillsdale, NJ: Erlbaum.

KUIPER, N. A., \& Rogers, T. B. (1979). The encoding of personal information: Self-other differences. Journal of Personality and Social Psychology, 37, 499-514.

LORD, C. G. (1980). Schemas and images as memory aids: Two modes of processing social information. Journal of Personality and Social Psychology, 38, 257-269.

MARKUS, H. (1977). Self-schemata and processing information about the self. Journal of Personality and Social Psychology, 35, 63-78.

MARKUS, H., \& SMITH, J. (1981). The influence of self-schemata on the perception of others. In N. Cantor \& J. F. Kihlstrom (Eds.), Personality, cognition, and social interaction. Hillsdale, NJ: Erlbaum.

Paivio, A. (1971). Imagery and verbal processes. New York: Holt, Rinehart \& Winston.

Paivio, A., Yuille, J. C., \& Madigan, S. (1968). Concreteness, imagery, and meaningfulness values for 925 nouns. Journal of Experimental Psychology Monographs, 76(1, Pt. 2).

ROGERS, T. B., KUIPER, N. A., \& KIRKER, W. S. (1977). Self-reference and the encoding of personal information. Journal of Personality and Social Psychology, 35, 677-688.

(Manuscript received for publication January 29, 1985.) 